Pesq. Vet. Bras. 31(2):136-138, fevereiro 2011

\title{
Dermatite por lambedura em bovinos no estado do Pará1
}

\author{
José Diomedes Barbosa², Carlos Magno Chaves Oliveira², Tatiane Teles \\ Albernaz ${ }^{2}$, Natália da Silva e Silva², José Alcides Sarmento da Silveira², \\ Alessandra dos Santos Belo Reis ${ }^{2}$ e Melina Garcia Saraiva de Sousa ${ }^{2}$
}

\begin{abstract}
Barbosa J.D., Oliveira C.M.C., Albernaz T.T., Silva N.S., Silveira J.A.S., Belo Reis A.S. \& Sousa M.G.S. 2011. [Licking dermatitis in cattle in the state of Pará, Brazil.] Dermatite por lambedura em bovinos no estado do Pará. Pesquisa Veterinária Brasileira 31(2):136-138. Central de Diagnóstico Veterinário, Universidade Federal do Pará, Rua Maximino Porpino da Silva 1000, Pirapora, Castanhal, PA 68743-080, Brazil. E-mail: diomedes@ufpa.br

A condition of 13 cattle from 10 farms in six districts in the state of Pará, Brazil, characterized by ulcerative skin wounds was studied. The lesions were observed in regions of the body to which the cattle had access with their own tongue; the animals licked the wounds frequently. Epidemiological studies, pathological findings and the differential diagnosis indicate that the dermatitis is caused by licking. The wounds healed after restraining the head of the animals that then were unable to lick themselves.
\end{abstract}

INDEX TERMS: Cutaneous lesions, skin, cattle, licking dermatitis.

RESUMO.- Foi estudada uma doença em 13 bovinos de 10 propriedades localizadas em seis municípios do estado do Pará, caracterizada por feridas ulcerativas da pele. A doença foi observada somente em regiões do corpo, aos quais os animais tinham acesso com a própria língua; também foi observado que os animais lambiam as feridas com freqüência. Os estudos epidemiológicos e patológicos desses casos, bem como o descarte dos diagnósticos diferenciais, permitiram concluir que se trata de dermatite por lambedura. Essas feridas sararam após a realização da contenção da cabeça dos animais, que desta maneira ficaram impossibilitados de lamber as mesmas.

TERMOS DE INDEXAÇÃO: Lesões de pele, bovinos, dermatite por lambedura.

\section{INTRODUÇÃO}

Em diversas fazendas, localizadas no estado do Pará, observam-se lesões na pele em diferentes regiões do corpo de bovinos, de etiologia desconhecida. Inicialmente suspeitou-se de causas parasitárias ou de fotossensibili-

\footnotetext{
${ }^{1}$ Recebido em 12 de agosto de 2010.

Aceito para publicação em 15 de setembro de 2010.

${ }^{2}$ Central de Diagnóstico Veterinário (Cedivet), Universidade Federal do Pará (UFPA), Rua Maximino Porpino da Silva 1000, Pirapora, Castanhal, PA 68743-080, Brasil. "Autor para correspondência: diomedes@ufpa.br
}

zação, o que foi descartado através do exame histológico de biopsias realizadas na pele com lesão nas áreas de transição das feridas e da epidemiologia. Com o surgimento de novos casos em diferentes propriedades percebeu-se que, em todos os casos observados as lesões encontravam-se somente em áreas onde o animal tinha acesso com a própria língua; daí foi levantada a hipótese que tais lesões eram produzidas pela ação mecânica da língua dos próprios animais. Observou-se também que essas lambeduras estavam associadas à época do ano em que havia uma maior infestação por ectoparasitas. Em consulta a literatura verificou-se que dermatite por lambedura já é diagnosticada em cães com causa variada inclusive por picadas de insetos. Em função disso, o presente trabalho teve como objetivo estudar a natureza dessas feridas e estabelecer a sua etiologia.

\section{MATERIAL E MÉTODOS}

Os dados epidemiológicos e clínico-patológicos foram obtidos em visitas a 10 propriedades localizadas em seis municípios do estado do Pará. Foram examinados 13 bovinos, com idade entre um e treze anos. No exame clínico, verificou-se a localização, natureza e extensão das lesões. Em dois animais foi realizada a contenção da cabeça para o lado oposto da ferida, com auxílio de corda, evitando-se que o animal lambesse a ferida. Também, realizou-se biopsia da pele de três bovinos afetados, na transição da pele lesionada e sadia. O material foi fixado em formol a $10 \%$ e processado rotineiramente e corado 
pela Hematoxilina-Eosina (HE) no Setor de Anatomia Patológica do Convênio "Projeto Sanidade Animal Embrapa/Universidade Federal Rural do Rio de Janeiro".

\section{RESULTADOS}

As feridas foram observadas em 13 bovinos, sendo 12 fêmeas e um macho, das raças nelore, guzerá e holandesa, também em mestiços das raças holandesa e simental. À inspeção dos animais foi verificado que a maioria apresentava escore corporal ruim. Dos 13 bovinos, 12 apresentavam uma única ferida e somente um animal apresentava três feridas. Essas feridas ocorriam somente em regiões do corpo onde os animais tinham acesso com a própria língua, como costado, membros, abdômen e dorso. Inicialmente observou-se mudança na direção dos pelos (Fig.1) e aglutinação dos mesmos pela saliva. Com a continuação das lambeduras havia perda dos pelos, em seguida o aparecimento de pequenas lesões nas camadas superfíciais da pele (Fig.2). Após o surgimento destas lesões iniciais havia uma maior atração de insetos para essa lesão o que estimulava ainda mais o animal a lamber-se,

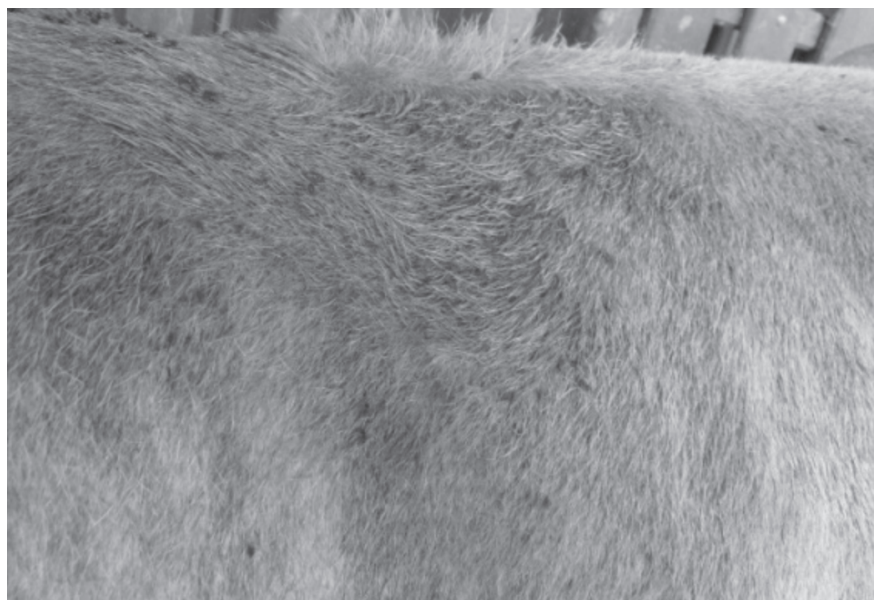

Fig.1. Bovino mestiço, fêmea com mudança na direção dos pelos na região do dorso causada pela lambedura.

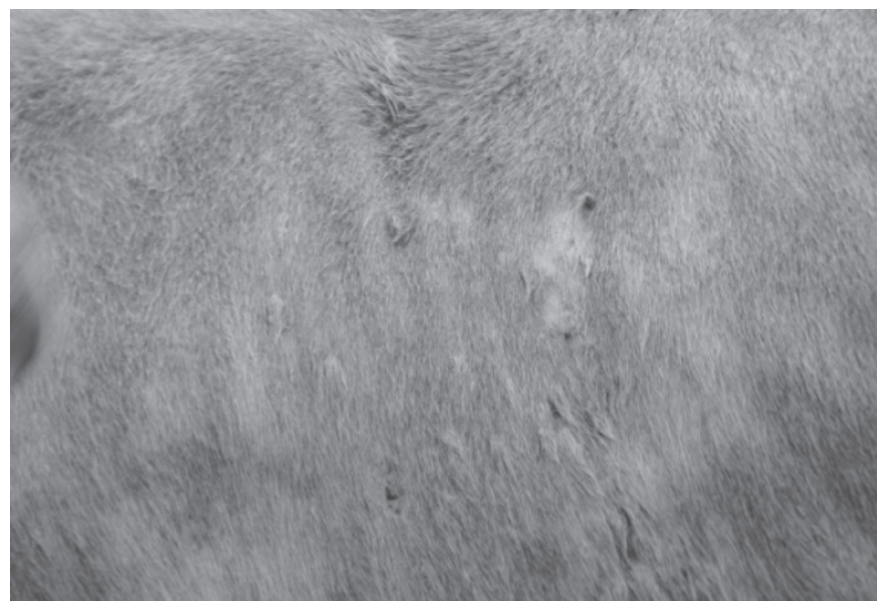

Fig.2. Animal da foto anterior com área de alopecia e perda da camada superficial da pele na região do costado.

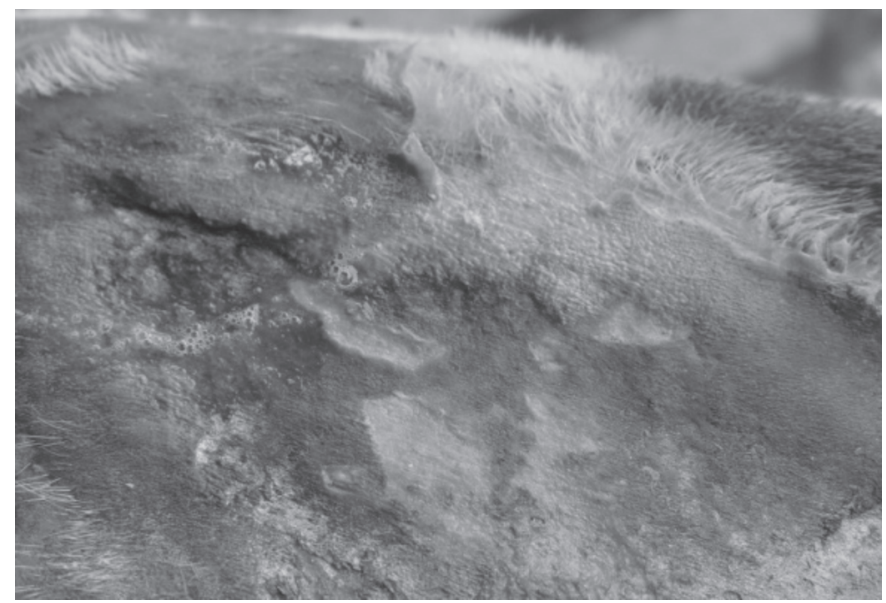

Fig.3. Bovino mestiço, fêmea com extensa ferida na região do dorso com perda de epitélio e presença de saliva.

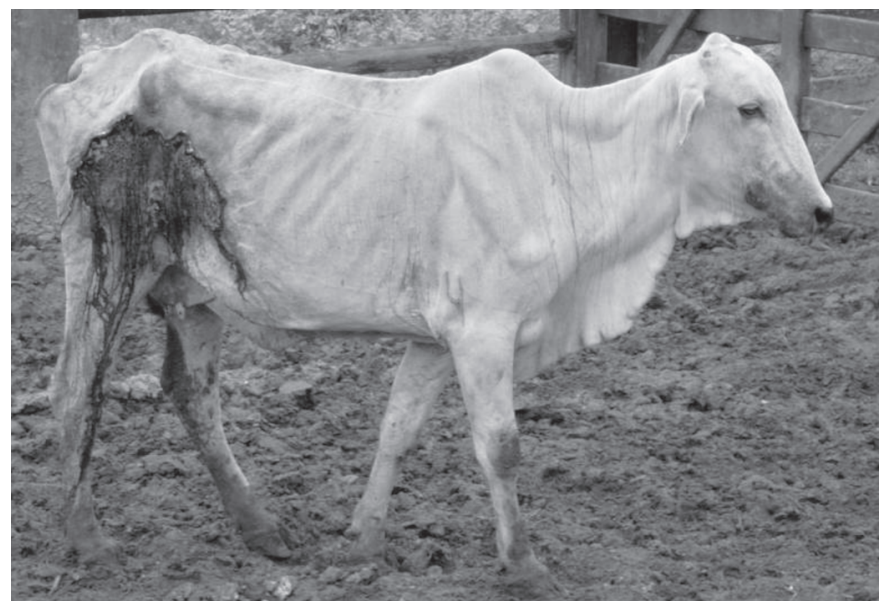

Fig.4. Bovino nelore, fêmea com extensa ferida de bordo irregular, de coloração avermelhada com exudação serossanguinolenta. Observa-se que a região ao redor boca está impregnada por secreção oriunda da ferida.

causando lesões mais profundas e extensas (aprox. $20 \mathrm{~cm}$ de diâmetro) na pele (Fig.3), o que provocava exsudação serossanguinolenta (Fig.4). Foi verificada também secreção sanguinolenta ao redor da boca dos animais acometidos (Fig.4). Nos dois animais que foram impossibilitados de ter o acesso a ferida, as mesmas diminuíram consideravelmente de tamanho. Em dois animais que apresentavam feridas em fase de cicatrização, os bordos ficaram esbranquiçados.

Os achados histopatológicos revelaram necrose superficial com formação de úlceras no derma, infiltrados inflamatórios não purulentos com presença de eosinófilos.

\section{DISCUSSÃO E CONCLUSÃO}

A dermatite por lambedura em cães e gatos consiste no lamber incessante de uma parte do corpo, até causar uma lesão na pele, que evolui para ulceração e exposição das camadas mais profundas, impedindo a cicatrização da ferida e predispondo à infecção secundária. Acredita-se existirem várias causas para este tipo de dermatite, dentre 
elas, as mais frequentes são: o stress, a dor articular e picadas de insetos (Scott et al. 1996). No entanto, não encontramos relatos na literatura da dermatite por lambedura em bovinos.

Provavelmente, essa dermatite em bovinos se inicia pela irritação da pele pela picada de insetos, o que ocasiona prurido, o que leva o animal a lamber o local. O lamber incessante leva a formação de uma pequena ferida, que evolui para ulceração da pele. Esse processo pode se agravar em função da característica áspera da língua dos bovinos.

Outro fator que chama atenção nessas feridas é a ausência de miíase, que pode ser explicada pelo fato dos animais lamberem constantemente as mesmas, com isso eliminarem os ovos depositados pelas moscas.

A presença de eosinófilos nos achados histopatológicos foi compatível com um processo alérgico, que possivelmente é causado pelas picadas dos insetos, semelhante à encontrada em ovinos e eqüinos com dermatite causada por picadas de insetos (Riek 1953, Connan \& Lloyd 1988, Yeruham et al. 2004, Corrêa 2005). A dermatite com infiltrado inflamatório de células mononucleares tem sido observada nos casos crônicos da doença e deve-se provavelmente ao autotraumatismo induzido pelo prurido e às infecções secundárias, que frequentemente ocorrem nos animais afetados, como também foi descrito por Corrêa (2005).

É necessário o diagnóstico diferencial com outras enfermidades que causam lesões semelhantes na pele de bovinos, sobretudo estefanofilariose, fotossensibilização hepatógena e carcinoma epidermóide.

A estefanofilariose é uma doença que também se caracteriza por lesões na pele de bovinos, porém essa enfermidade é causada por um nematódeo do gênero Stephanofilaria (Johnson et al. 1981), o qual não foi observado no exame histopatológico e no exame direto, através de esfregaço da ferida.

Na fotossensibilização hepatógena os animais apresentam lesões com desprendimento da pele, também em outras regiões do corpo, preferencialmente despigmentadas, além da lesão hepática (Schild 2007) o que não foi verificado no presente estudo.
O carcinoma epidermóide é uma neoplasia maligna originada dos queratinócitos da camada escamosa do epitélio da pele (Weiss \& Freze 1974, Fernandes 2007), que também se caracteriza por eritema e ulceração. Porem exame histopatológico permite a diferenciação.

Baseado no conjunto dos dados, isto é, epidemiologia, localização das feridas somente em regiões do corpo dos bovinos, aos quais eles têm acesso com a própria língua, no fato do animal lamber com frequência a ferida, na recuperação das feridas após o impedimento das lambeduras, na eliminação dos diagnósticos diferenciais e nos achados histopatológicos, concluímos tratar-se de dermatite por lambedura.

\section{REFERÊNCIAS}

Connan R.M. \& Lloyd S. 1988. Seasonal allergic dermatitis in sheep. Vet. Rec. 124:335-337.

Corrêa T.G. 2005. Etiologia e epidemiologia da dermatite alérgica sazonal em ovinos no sul do Rio Grande do Sul. Dissertação de Mestrado em Parasitologia, Departamento de Microbiologia e Parasitologia, Instituto de Biologia, Universidade Federal de Pelotas, RS. 47p.

Fernandes C.G. 2007. Neoplasias em ruminantes e eqüinos, p.650656. In: Riet-Correa F., Schild A.L., Lemos R.A.A. \& Borges J.R.J. (Eds), Doenças de Ruminantes e Eqüídeos. 3ª ed. Palloti, Santa Maria, RS.

Johnson S.J., Parker R.J., Norton J.H., Jaques P.A. \& Grimshaw A.A. 1981. Stephanofilariasis in cattle. Aust. Vet. J. 57:411-413.

Riek R.F. 1953. Studies on allergic dermatitis (Queensland itch) of the horse: Description, distribution, symptoms and pathology. Aust. Vet. J. 29:177-181.

Schild A.L. 2007. Fotossensibilização hepatógena, p.39-42. In: RietCorrea F., Schild A.L., Lemos R.A.A. \& Borges J.R.J. (Eds), Doenças de Ruminantes e Eqüídeos. Vol.2. $3^{\underline{a}}$ ed. Pallotti, Santa Maria, RS. 694 p.

Scott D.W., Miller Jr W.H. \& Griffin C.E.1996. Dermatologia de Pequenos Animais. 5 $5^{\text {a }}$ ed. Interlivros, Rio de Janeiro, RJ. 1130p.

Weiss E. \& Freze K. 1974. Histological classification of tumors of domestic animals: Tumors of the skin. Bull. World Health Org. Int. 50(1/2):79-100.

Yeruham I., Perl S. \& Braverman Y. 2004. Seasonal allergic dermatitis in sheep associated with Ctenocephalides and Culicoides bites. Vet. Dermatol. 15:377-380. 